\title{
Spatio-Temporal Analysis of Flood Incidence in Nigeria and Its Implication for Land Degradation and Food Security
}

\author{
Taiye Oluwafemi Adewuyi ${ }^{1} \&$ Emmanuel Ajayi Olofin ${ }^{2}$ \\ ${ }^{1}$ Department of Geography, Nigerian Defence Academy, Kaduna, Kaduna State, Nigeria \\ ${ }^{2}$ Department of Geography, Bayero University, Kano, Kano State, Nigeria \\ Correspondence: Taiye Oluwafemi Adewuyi, Department of Geography, Nigerian Defence Academy, PMB \\ 2109, Kaduna, Kaduna State, Nigeria. Tel: 234-803-700-2821. E-mail: taiyeadewuyi@yahoo.com
}

\author{
Received: October 31, 2013 Accepted: November 26, $2013 \quad$ Online Published: January 15, 2014 \\ doi: $10.5539 /$ jas.v6n2p150 \\ URL: http://dx.doi.org/10.5539/jas.v6n2p150
}

\begin{abstract}
This study characterises the pattern of flood incidences in the year 2012 across Nigeria with the aim of establishing the implications on land degradation. The results revealed 52 major flood incidences within 88 days: 20 incidences occurred on separate days, 16 as double per day, and 12 as triple events while 4 occurred in a day. The spatial distributions are: North Central geopolitical zone recorded 31\%, South South 21\%, North West $17 \%$, North East $15 \%$, South East $12 \%$ and South West $4 \%$ respectively. Other characteristics are the duration of the flood: $38 \%$ of the flood incidents lasted for more than 14 days, $27 \%$ for $1-3$ days, while $27 \%$ for $4-7$ days respectively and $8 \%$ was recorded for $8-14$ days duration, while the frequency of occurrence revealed that July has 2 incidents, August (16), September (24) and October (10). The floods affected mostly states adjacent to the major rivers and in many instances aggravated land degradation through erosion, pollution and removal of vegetation, though the pattern and intensity differed across the various geopolitical and ecological zones of the country. Consequently, it affected food production and many farmers were left with nothing or little to harvest for food and to cater for their well being. This makes food insecurity unavoidable both in the short and long run. Therefore, there is the need for government at various levels and communities to be proactive in the management of floods in the country in order to avoid greater problems in the future through land use planning, education and adequate warning system.
\end{abstract}

Keywords: agriculture, flood incidence, flooding, food security, land degradation

\section{Introduction}

The maintenance of a high quality environment is at the heart of human prosperity both in terms of economic and healthy living (Adewuyi, 2011). Of recent however, a high quality environment has become increasingly difficult to attain. The issues are the same all over the world. The trend is that of decline in environmental quality, which environmentalists generally call degradation. Degradation of the environment occurs in different parts of the world in different forms. It occurs mainly in the form of deforestation, erosion, desertification, massive flooding, global warming, wild fire and uncertain biochemical and hydrological cycles. For example, the World Resources Institute [WRI], (1997) estimated that the whole world's lost an average of 9391000 hectares of forest within ten years $(1990-2000)$ to environmental degradation amounting to 0.2 percent of the worlds land area. Another report revealed that since the end of the last ice age, approximately half of the world's forest cover has been lost (Kapos, 2000) which eventually affects food supply.

Food security can be defined from many perspectives because it can be approached through many areas. Famous among these perspectives are the definitions of Maxwell and Smith (1992) where about 200 definitions were reviewed; Maxwell (1996) \& Food Agricultural Organisation [FAO] (1983). However, this study settles for the definition of FAO, 2002 'as a situation that exists when all people, at all times, have physical, social and economic access to sufficient, safe and nutritious food that meets their dietary needs and food preferences for an active and healthy life'.

Mwaniki (n.d.) reports that the major challenge to food security in Africa is its underdeveloped agricultural sector that is characterized by over-reliance on primary agriculture, low level of soil fertility, minimal use of external farm inputs, environmental degradation, significant food crop loss both pre- and post- harvest, minimal value addition and product differentiation, and inadequate food storage and preservation that results in significant 
commodity price fluctuation. Ninety five percent of the food in Sub-Saharan Africa is grown under rain fed agriculture (InterAcademy Council (2004)). Hence, food production is vulnerable to adverse weather conditions. United Nations Economic Commissions for Africa [UNECA] (2012) concluded that despite good performance with high economic growth rates over the last decade, Africa has not made significant progress on some of its major challenges, especially food security and employment for the growing youth population. Consequently, later in 5.2, food security for Nigeria will be examined using the four pillars upon which it is built, namely: food availability, access, stability and use (United Nations [UN], 1975; FAO, 1983; UNECA, 2012).

Several definitions of land degradation have been proposed. Not surprisingly, these definitions cover a breadth of topics, many spatial and temporal scales of interest, and represent desperate viewpoints. In general, the various definitions differ in their emphasis on the meteorological, ecological, and human dimensions of the problem. The summary of all the definitions revolves around change in the structure and functioning of local or regional agro-ecosystems that, first, may or may not be caused by human activity; secondly, when in fact caused by human activity, have causes that may be either local (e.g. clearing of land) or global (e.g. institutional causes like trade agreements, or biophysical causes like climate change which of recent has resulted to massive floods in many parts of the world), and thirdly, regardless of the causes, may or may not have an impact on human activities at these different scales. Therefore, land degradation is an integrated concept.

Other concepts of land degradation are the spatial and temporal scale of operation. While some studies are farm and settlement based (Abel, 1993; Hiernaux \& Turner, 2002), others are national, regional and global (Dean \& MacDonald, 1994; Ash, Stafford, \& Abel, 2002; Xue \& Fennessy, 2002). The temporal scale also varies from one study to another. Some also view land degradation from the perspective of sustainability (Pretty, 1994; Redcliff, 1999; Sneddon, 2002). Consequently, land that cannot sustain long economic yield for both present and future land users are claimed to be degraded. Other concepts of land degradation are potentialities and productivities which are preferably discussed later.

Some attempts have been made by scholars to classify the level of land degradation. The aim of the classification of degraded land is to design corresponding ameliorative measures for sustainable development of the environment. Such attempts include United Nations Environmental Program [UNEP] (1985); Mortimore (1989); Olofin (1997); Edosowman and Aigbe (1998); Mallo (2000). For example Olofin (1997) classifies land degradation into three categories: slight, moderate and severe or chronic degradation. Going into the details and considering soil as an entity in land degradation, FAO (1993) classified land use into two classes namely; sustainable land and unsustainable land. To FAO (1980) cited in Fagbami and Ogunkunle (2000), land degradation was classified based on soil potentiality in Nigeria into five classes namely; strong potentialities, good potentialities, medium potentialities, slight potentialities and no potentialities. Similarly, the organization also classified land based on present agricultural productivity in Nigeria as follows: very high productivity, high productivity, medium productivity, low productivity and no productivity.

Classification of land degradation can also be done according to the impact level. This includes farm/household level, community or village, district/provincial and national. This particular method of classification is important because it reveals the extent of impact of the degradation on population and economy (including agricultural activities). The larger the level, the higher the impact and the more difficult it will be to reverse the effect because of the technology and financial commitment that will be required.

Having reviewed the theoretical framework of land degradation as a whole and with focus on Nigeria, it is particularly important to further examine the role of the flooding incidences in the year 2012, by characterizing the flooding in terms of spatial and temporal patterns, duration and intensity, and its implication on land degradation and food security in the various ecological zones of Nigeria and under different land use and cover.

Just like land degradation and food security, many definitions exist for floods. They are however, generally considered as extreme hydro-meteorological events, which result in the inundation of usually dry places by a great quantity of water. Flood is also described as a state of overbank-full discharge of a river. This implies it is a period of high discharge of a river resulting from conditions such as heavy precipitations, sudden melting of snow, ice and the collapse of dams and barrages. When floods occur, the flow capacity of rivers and absorptive capacity of soils are exceeded. As a result, it begins to negatively affect the land and its major components namely: soil as well as vegetation which constitutes and hosts most living things and a major component of the environment that is used for agriculture.

Flooding on large, medium or small scales has enormous consequences on the environment, life and property. The effect of flooding can never be over emphasized because it has immediate and long term effects on the environment and food production. These effects have physical, social, economical, medical and security 
implications on man (Adewuyi \& Baduku, 2012). However, many reasons have been attributed to cause climate change in general and the wide spread flooding in Nigeria in particular. However, the arguments forwarded are not based on facts, neither are they derived from empirical studies but merely on views that are mostly politically motivated. Even when researchers have tried to investigate it, they face the challenge of not having comprehensive data for their research. It is this problem that we eventually intend to solve, but currently the intention is to characterise the flood incidences for 2012, making it a baseline data since such data do not exist. The intention is also to examine its implication on land degradation and food security as a starting point.

As a result, there is an urgent need to examine land degradation from the perspective of 2012 flood incidences (which in many circles is perceived to be unusually high in occurrence and intensity) and more importantly its implication on sustainable development with particular attention on food security. This constitutes the aim of this study, and it is intended to be achieved by first, establishing the temporal and spatial characteristics of flooding in the year, and secondly, estimating the size of the area affected, duration of the flood, intensity and its implication on land degradation and food security.

The focus in this paper is on flood incidences of year 2012 and only on flooding that lasted more than 24 hours. This is so, because flood database for the entire country does not exist before now and flood that lasted less than a day may not significantly affect food production and security. The study for the paper uses descriptive statistical techniques for analysis. The justification for this study is that, Nigeria as a nation needs to know the pattern of all sources of environmental degradation, establish a databank to monitor these events, and also be in a position to forecast their intensity, spread and consequences on man and his environment. Consequently, Nigeria will be in a position to prevent small, medium and large scale ecological disasters, and to conserve its environment for sustainable development.

\section{Area Description}

This study is limited to only Nigeria, located in West Africa, within latitude $4^{\circ} 20^{\prime} \mathrm{N}$ to $14^{\circ} 00^{\prime} \mathrm{N}$, and longitude $2^{\circ} 45^{\prime} \mathrm{E}$ to $14^{\circ} 40^{\prime} \mathrm{E}$, with an area of $923768 \mathrm{~km}^{2}$ of which $910768 \mathrm{~km}^{2}$ is land and $13000 \mathrm{~km}^{2}$ is coastal area. The land area is shared among the forest/mangrove, savannah and semi-arid zones. The elevation varies across the country rising up to $3000 \mathrm{~m}$ above mean sea level in few instances along the Adamawa and Taraba state axes. The seasons and patterns of rainfall vary across the country for obvious reasons, which have also affected the land use and cover distribution. The coastal/southern area has the highest rainfall ranging from 1500 and $4000 \mathrm{~mm}$, while the mid-belt and the extreme north have rainfall ranging from 600 to $1400 \mathrm{~mm}$. High temperature and humidity as well as marked wet and dry seasons characterise the Nigerian climate.

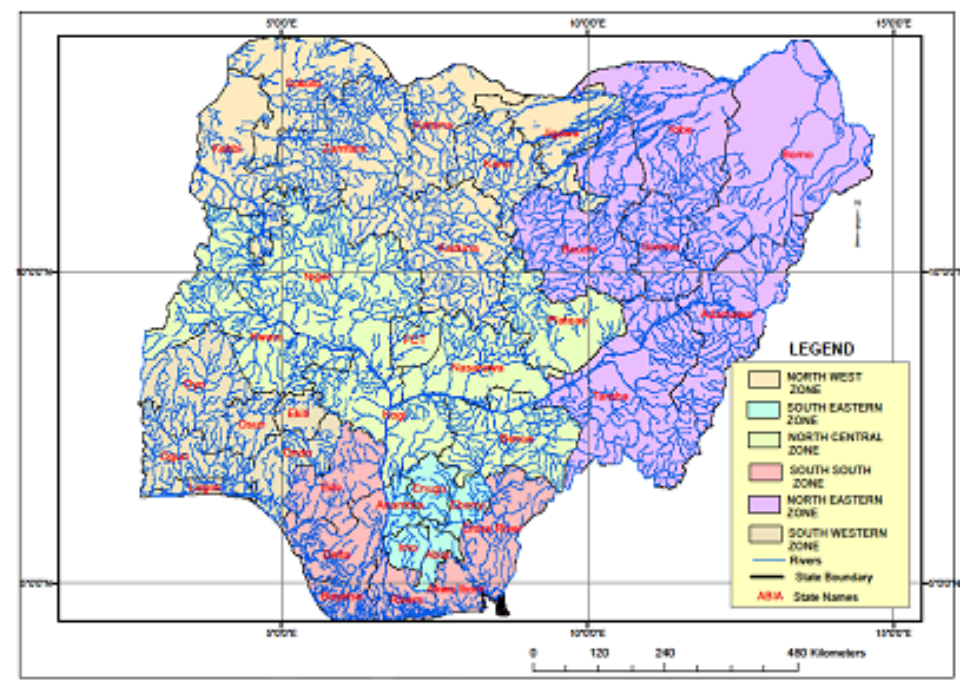

Figure 1. Drainages network and the geopolitical zones of Nigeria

The hydrology of Nigeria is dominated by two great river systems, the Niger-Benue and the Chad system. With the exception of a few rivers that empty directly into the Atlantic Ocean, all other flowing waters ultimately find their way into the Chad basin or down the lower Niger to the sea. The vegetation of Nigeria is also diverse from mangrove/ high forest in the south to savannah in the mid-belt and grassland in the extreme north. Also diverse is 
the vegetal cover density across the country. The population of the country stands at about 170.1 million people (Population Reference Bureau [PRB], 2012a) with majority depending on agriculture directly or indirectly for survival both in the rural and urban centres. Figure 1 further illustrates the geographical location of Nigeria, the geopolitical zones and major rivers in the country.

\section{Materials and Methods}

The types of data for the study are both primary and secondary in nature. The primary data are photographs, personal observation and interviews, which are sourced directly by the researchers, while the secondary data are information collected from Newspaper, Radio, Television and the Internet. These data are collected by reading at least five national newspapers daily during the rainy season, and listening to national news on Nigerian Television Authority (NTA), African Independent Television (AIT) and Channels Television stations and direct phone calls to contacts in areas where there is flood. Additional information was gathered through the multi-media on flooding incidences in Nigeria in 2012.

For the photography, CASIO 101 digital cameras were used to acquire the photographs while semi-structured questions were employed for the interview. The geometrical data analysis and presentation was done using ArcGIS 10.1 and SPSS software. The analysis begins with initial collation of collected data according to states, then geopolitical zones, land use and cover, frequency of flood, intensity of flood, size of area affected and whether or not it affected state capitals. An abridged version of the collated data is presented in Table 1.

\section{Results}

The results are presented from two perspectives:

\subsection{Spatial and Temporal Distribution of Flood Occurrence}

From Table 1, it is evident that all the geopolitical zones were affected by floods in the year. Further examination revealed that under the category of duration for $1-3$ days, all the geopolitical zones were affected except for North Central (NC), with 12 states affected as indicated, five of them are from South West (SW) alone while the remaining 7 states are spread over four other 4 zones. Under the category of floods with duration of $4-7$ days, 9 states were affected, spreading across 4 geopolitical zones with North Central zones dominating having 4 states, while South East (SE) and South - South (SS) are not having any. The category of $8-14$ days duration shows that 5 states were affected cutting across 4 geopolitical zones with none of them dominating. The last category, which was for floods with duration greater than 14 days, revealed that 4 states were affected and these were also restricted to Niger delta area (SS and SE).

The knowledge derived from all of this is that the flood of lower duration (1- 3 days) affected all the zones except for $\mathrm{NC}$ because of the terrain which is generally higher than other places. As the duration of the flood increased, the floods spread further. It then began to concentrate along states that border the major rivers. This explains why floods for duration greater than 14 days are concentrated in the SS and SE which are situated at the lower end of the River Niger and the delta from where water is discharged to the Atlantic Ocean. This was also shown in Figure 3 with a large area affected by flood in both the SS and SE. In terms of the location, irrespective of the length of duration, the NC had the highest incidents of flood (16), followed by SS (11), then NW (9), NE (8), SE (6) and SW (2). This also reveals that zones adjacent to the two major rivers and the rivers draining Nigeria into Lake Chad are the most affected zones. This explains why SW which has no boundary with the rivers recorded only two incidences.

Table 1 provides information on the temporal distribution of floods for the year. The analysis reveals that the month of September recorded the highest flood event across the six geopolitical zones with a total of 26 occurrences which translate to $50 \%$ of total occurrences. It was followed by August with 16 occurrences (31\%), October, 8 occurrences (15\%) and July, 2 occurrences (4\%), with the week of $23-29$ September having the highest occurrence of $9(17 \%)$ as indicated in Figure 2. In the months of July and October, flood occurrences were reported in only some zones. The implication of this is that warning systems should be initiated for residents along the flood plain from the beginning of the month of July. 


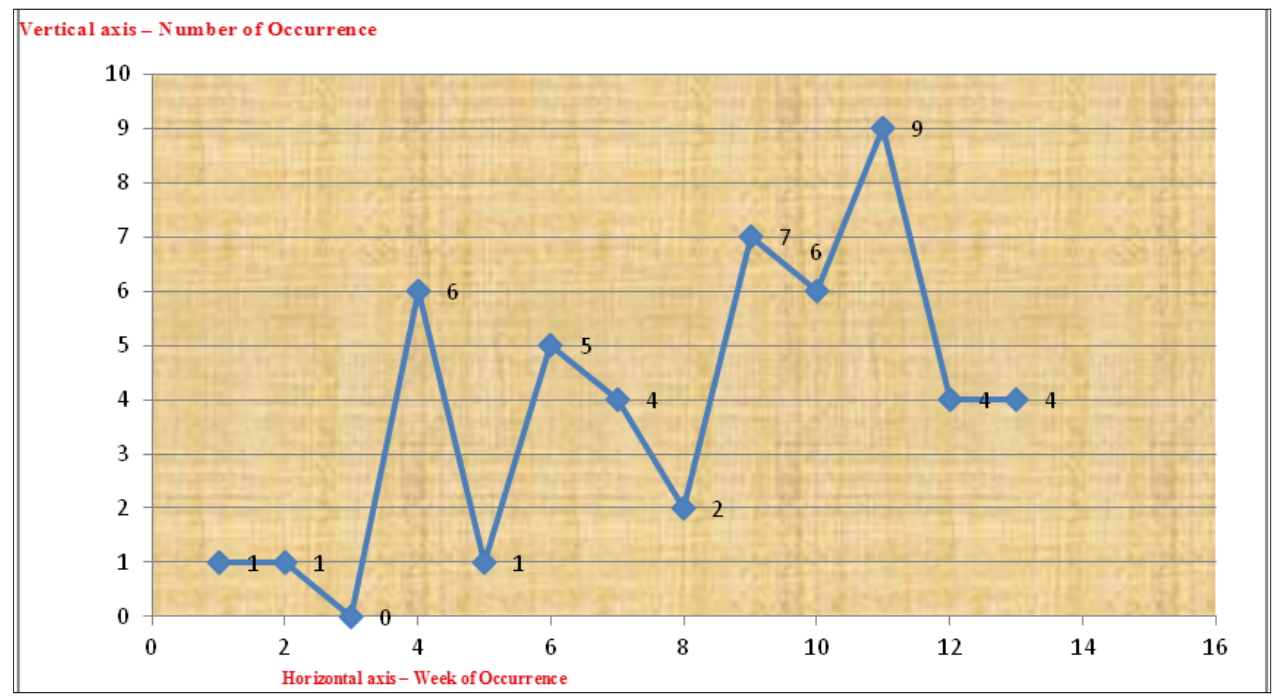

Figure 2. Frequency distribution of flood incidence

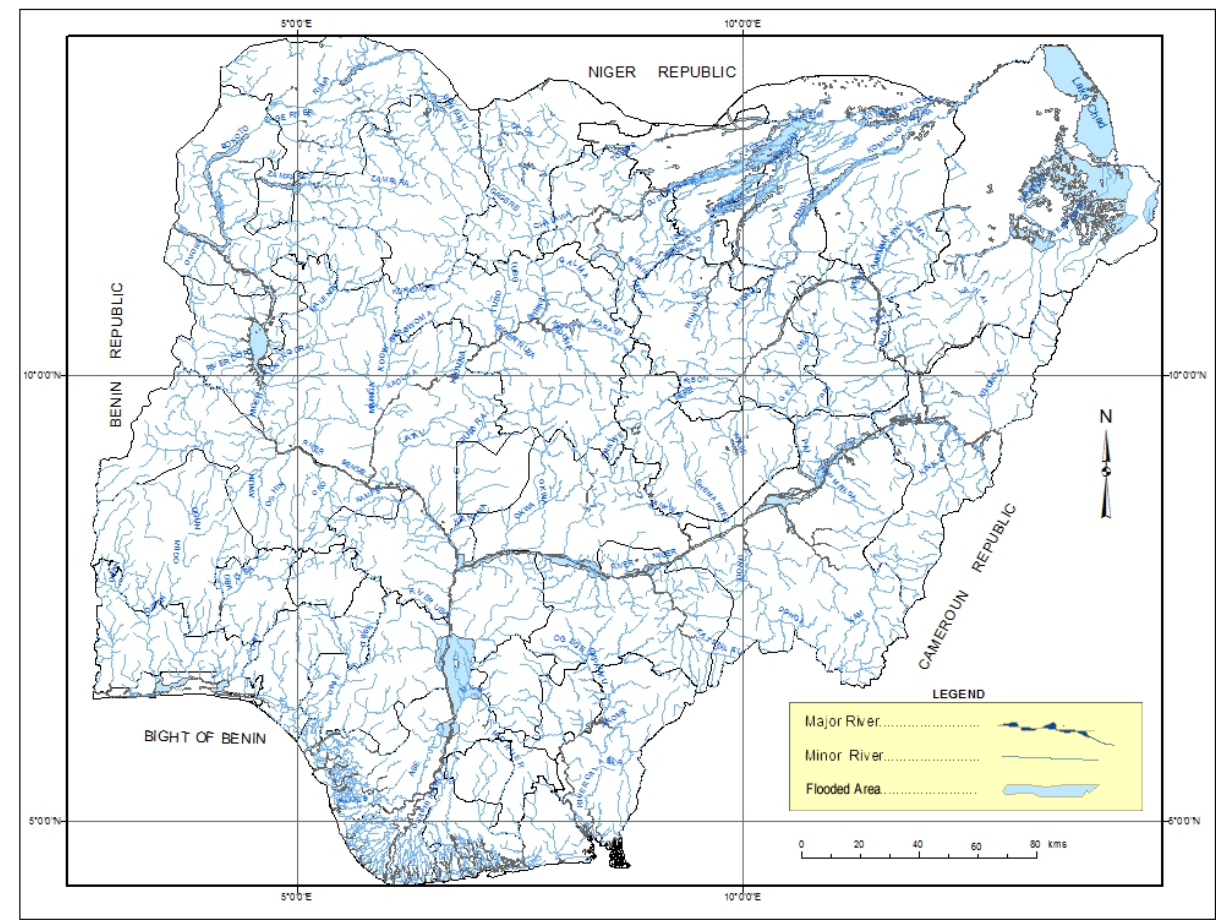

Figure 3. Areas most affected by flood

\subsection{Area Covered and Intensity of Flood}

Based on the documentation in Table 1, a rough estimation of the area covered by the flood was undertaken, only to give a hint on the extent and not necessarily the actual cover. Since the event in most cases cannot be mapped using conventional survey methods, a broad classification was adopted using 'large' for areas less than or equal to $100 \mathrm{~km}^{2}$ and 'very large' for areas greater than $100 \mathrm{~km}^{2}$. Using simple arithmetic and assumptions, putting the average for the two classifications to be $50 \mathrm{~km}^{2}$ and $100 \mathrm{~km}^{2}$ and multiplying them with their respective total number of occurrences (10 and 42), the estimated area covered across the country was $4,700 \mathrm{~km}^{2}$. This value translates to $0.51 \%$ of total land mass of Nigeria. This value is more than $0.2 \%$ for the world land reported by WRI (1997) for $1990-2000$.

The North Central (NC) zone has the highest area covered and the South West (SW) the lowest, while other zones have almost equal coverage. This size can only be authenticated using remote sensing methods. However, this size 
is assumed to be very conservative, when compared to the number of occurrences that were recorded, the number of states affected, the terrain in some areas, particularly in the far north and the amount of damages to lives and property and in particular farmlands. While based on land cover/use, there are 10 incidences in the urban environment, 30 in rural and 12 in mixed urban/rural areas with 15 of the incidences affecting state capitals. This further explains the pattern for the year. Figures $4 \mathrm{a}$ and $4 \mathrm{~b}$ give some pictorial illustrations of the flood.

Table 1. Summary of Flood Incidences in Nigeria for 2012

\begin{tabular}{|c|c|c|c|c|c|c|c|c|c|c|c|c|c|c|c|c|c|c|c|}
\hline \multirow{2}{*}{$\begin{array}{l}\text { Geopolitical } \\
\text { Zone of } \\
\text { Nigeria }\end{array}$} & \multicolumn{4}{|c|}{ Monthly Frequency } & \multicolumn{4}{|c|}{$\begin{array}{l}\text { Numbers of } \\
\text { Incidences/Day }\end{array}$} & \multicolumn{4}{|c|}{$\begin{array}{l}\text { Intensity based } \\
\text { on Duration in days }\end{array}$} & \multicolumn{3}{|c|}{$\begin{array}{l}\text { Broad Classification-Land } \\
\text { Use/Cover }\end{array}$} & \multicolumn{2}{|c|}{ Area Coverage } & \multicolumn{2}{|c|}{$\begin{array}{l}\text { State } \\
\text { Capital }\end{array}$} \\
\hline & July & Aug & Sept & Oct & 1 & 2 & 3 & $\geq 4$ & $1-3$ & $4-7$ & $8-14$ & $>14$ & Urban & Rural & Both & $\begin{array}{l}\text { Large } \\
\leq 100 \\
\mathrm{~km}^{2}\end{array}$ & $\begin{array}{l}\text { Very } \\
\text { Large } \\
>100 \\
\mathrm{~km}^{2}\end{array}$ & Yes & No \\
\hline NW & - & 5 & 4 & - & 9 & - & - & - & 5 & 3 & 1 & - & 3 & 4 & 2 & 1 & 8 & 3 & 6 \\
\hline $\mathrm{NE}$ & - & 2 & 6 & 1 & 8 & - & - & - & 1 & 3 & 3 & 1 & 1 & 4 & 3 & - & 8 & 1 & 7 \\
\hline $\mathrm{NC}$ & 1 & 5 & 10 & - & 14 & 2 & - & - & 7 & 3 & - & 6 & 2 & 8 & 6 & - & 16 & 8 & 8 \\
\hline SW & 1 & 1 & - & - & 2 & - & - & - & 1 & 1 & - & - & 2 & - & - & - & 2 & 2 & - \\
\hline SE & - & 1 & 3 & 1 & 6 & - & - & - & - & 2 & - & 4 & 1 & 5 & - & 4 & 2 & - & 6 \\
\hline SS & - & 2 & 3 & 6 & 9 & 2 & - & - & - & 2 & - & 9 & 1 & 9 & 1 & 5 & 6 & 1 & 10 \\
\hline Total & 2 & 16 & 26 & 8 & 48 & 4 & - & - & 14 & 14 & 4 & 20 & 10 & 30 & 12 & 10 & 42 & 15 & 37 \\
\hline Percentage & 4 & 31 & 50 & 15 & 92 & 8 & - & - & 27 & 27 & 8 & 38 & 19 & 58 & 23 & 19 & 81 & 29 & 71 \\
\hline
\end{tabular}

Data collated from print and electronic media, namely: The Sun, Thisday, The Nation, Tribune, Daily Trust, Leadership, NTA, AIT, Channels TV and FRCN.

NC - Benue, Kogi, Kwara, Nasarawa, Niger, Plateau states and FCT.

NE - Adamawa, Bauchi, Borno, Gombe, Taraba and Yobe states.

NW - Kaduna, Kano, Katsina, Kebbi, Jigawa, Sokoto and Zamfara states.

SE - Abia, Anambra, Ebonyi, Enugu and Imo states.

SS - Akwa Ibom, Bayelsa, Cross Rivers, Delta, Edo and Rivers states.

SW - Ekiti, Lagos, Ogun, Ondo, Osun and Oyo states.

As for the intensity based on duration, Table 1 indicates that $20(38 \%)$ of the flood incidences persisted for more than 14 days, while only 4 incidences were recorded for a duration of $8-14$ days ( $8 \%), 8$ for $4-7$ days $(27 \%)$ and 8 also for 1 - 3 days (27\%) respectively. While most parts of the country were affected by the flood, the southern axis of the country suffered most with 13 of the incidences, falling under the category of intensity of greater than 14 days, taking place in the Niger delta region (SS and SE) with an area far less than other geopolitical zones. The next is the NC with 6 occurrences, which is understandable because not only do two major rivers dissect the zone, they also merge in the zone at Lokoja. The other categories are fairly distributed among the zones, though NC and NW have a slight edge over others.

Finally, most of the flood occurred on different days. Only on four occasions was a double incidence of flood recorded for the entire 4 months under study. Two each were recorded in the NC and SS geopolitical zones, which further corroborate earlier results.

\section{Discussion}

\subsection{Implication for Land Degradation}

The implication of the flood event for the year is not the same across the country. It varies according to the ecological zone, land use and land management/conservation techniques in place. For the semi arid zone in the far northern part of the country (parts of $\mathrm{NE}$ and $\mathrm{NW}$ ), the problems are basically erosion and devegetation. Three types of erosion occurred in the area and they are evident through washing away of farmland, accumulation of sand at the bottom of any object and siltation of drainages. 
These effects are most common particularly around the fringes of settlement where there is intensive land use for both agriculture and developmental projects. Figures $4 \mathrm{c}$ and $4 \mathrm{~d}$ show few instances. When this is considered alongside the pending problems of desert encroachment and insecurity in these areas the consequences are wind erosion during dry season and also erosion of all kinds during the wet season.

For the savannah zone in some parts of the north, the mid-belt and parts of the southern states (which cover about $50 \%$ of the total area of Nigeria and constitute the food basket of the country, as well as featuring the two major rivers of Niger and Benue traversing through them before joining at Lokoja), the flood events portend a lot of consequences for the area. Firstly, the duration of the flood event is higher than that of the arid zone. Secondly, it covers a wider area, and thirdly, it carries a lot of force due to the volume of water and the topography of much of the area. Consequently, there are many gully sites and distortion of the surface morphology. An additional effect was the destruction and washing away of surface cover which was evident throughout the area after the flood waters receded (Figures $4 c-4 d$ ).

The forest area is predominantly in the southern part of the country and this is where we had the longest duration of flood with many areas under water for more than 14 days. Though the area has a better land cover, there was gully erosion along drainages and roads of all categories. Finally, the issue of pollution from both solid and sewage waste affected all the 3 ecological zones (Figures $4 \mathrm{c}$ and $4 \mathrm{~d}$ ).

Generally, the floods affected rural areas (where land use/cover has been changed mostly to agricultural use) more than the urban areas. Consequently, this change exposes the rural land to damage by the flood. Since in many places the surface soil and crops are already washed away, the quality of the land is further degraded and agricultural productivity is reduced which may also result to food shortages and insecurity if appropriate conservation is not applied in time. With the flood affecting $0.51 \%$ of Nigeria's land across various ecological zones, there is indeed urgent need for actions to protect the land.

That the flood ravaged 9 state capitals, which are among the major urban centres of the country, corroborates the massive loss of life and properties reported by many. Figure $4 \mathrm{~b}$ shows a typical situation where a whole neighbourhood was submerged under water while Figure $4 \mathrm{c}$ shows the consequences of such events, consisting of gully erosion site, and sand and waste littering the damaged street.

From this assessment, using Olofin's (1997) categorisation, the land degradation resulting from the flood incidences can be categorised as between slight and moderate degradation, which implies the negative consequences of the flood can be reversed and it can be done cheaply and with available technologies and expertise in the country. When the degradation is examined from the perspective of FAO 1993, the land in the semi-arid area of the north can be classified as a sustainable land but for a short period, that of the savannah in the middle belt for a medium term, while the forest/mangrove area of the southern area is sustainable for a long time.

It is therefore necessary for various government agencies like the National Emergency Management Agency (NEMA), their state counterparts, the Ministry of Environment, the Fire Service, the Police, and others to begin to synergise by utilising various information now available on land degradation in the country including the one from this study for adequate land use/cover planning to ameliorate existing processes of land degradation in the country.

Other measures should include massive educational awareness of the short and long term effects of floods and land degradation to the citizens of the country at large in all its ramifications. Lastly, the various emergency agencies and allied disciplines need to begin to use information from studies like this to make adequate plans on how to handle various circumstances that may emanate from future floods in order to protect lives and properties and make the Nigerian environment sustainable and beneficial to the children yet unborn.

\subsection{Implication on Food Security}

This study revealed that the flood affected both rural areas and the fringes of urban centres where agricultural activity is very intense. It cut across all the ecological zones by washing away crops thereby affecting all the crops grown in the country. It also affected key infrastructure like roads and bridges which were washed away, and resulted in a break in the transport connections that linked farming communities where crops are grown and taken to city centres where they are mostly consumed. Lastly, the processes of erosion of fertile surface soil, removal of surface cover and pollution of farmland with waste give rise to an increase in the price of agricultural produce. Such was the case in the year under review. 


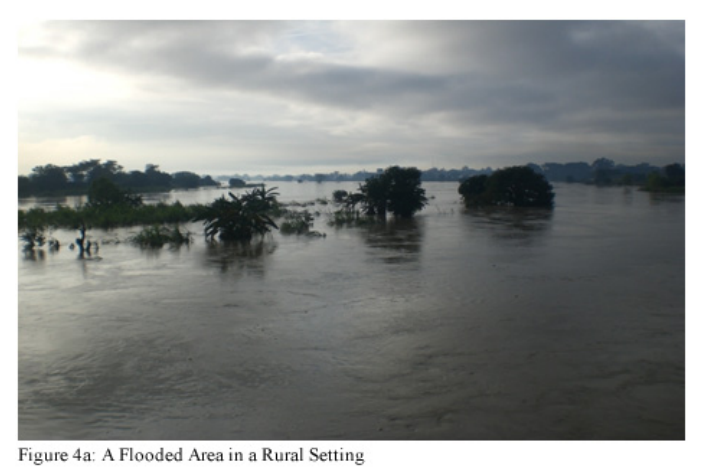

Figure 4a. A flooded area in a rural setting

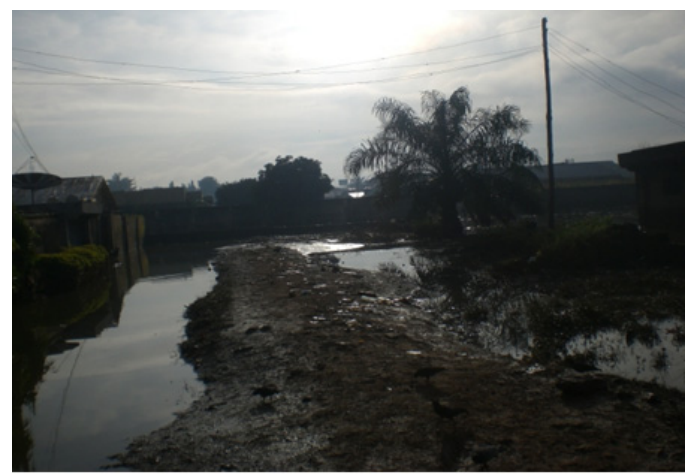

Figure 4c: Erosion and Waste Deposit in an Urban Area

Figure 4c. Erosion and waste deposit in an urban area



Figure 4b: A Flooded Area in an Urban Setting

Figure $4 \mathrm{~b}$. A flooded area in an urban setting

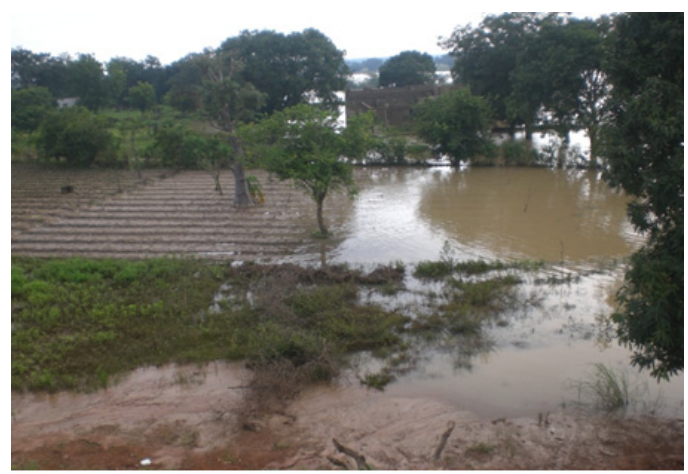

Figure 4d: Fertile Surface Soil and Crops of Farmland Washed Away

Figure 4d. Fertile surface soil and crops of farmland washed away

From the effects of the flood on Nigeria just listed in the preceding paragraph, the three pillars as indicated by UN, 1975 and FAO, 1983 (availability, accessibility and use) upon which food security stands were seriously affected in the study area. Consequently, there began to be a distortion in the equilibrium between supply and demand of agricultural produce particularly in the rural area where their major source of income comes.

When the result of this study is also considered with projections of PRB (2012b) on Population and Food Security: Africa's Challenge (which states that the number of hungry people continues to rise, and doubts if Africa will be able to meet its future food needs) then Nigeria with 170.1 million people in 2012 (with projections for 2025 and 2050 put at 234.4 million and 402.4 million respectively according to PRB (2012a)) is in serious danger of food insecurity in the short and long term if this trend continues.

It is therefore the opinion of this study that suggestions already given to reduce the effect of flood on land degradation be taken seriously and adopted immediately since the effect of flood now goes beyond just degradation of the environment but also has serious socio-economic implication on the country in terms of food security. Another suggestion is to ensure that key infrastructures damaged by the flood are repaired or replaced and crops with resistance to flood and other ecological problems are developed and planted in areas prone to flood. Finally, failure to resolve the consequences of the flood may aggravate the already complex issues of internal security across the country, because a hungry man is an angry man, and this may also spill over to the neighbouring countries.

\section{Conclusion}

This study has established the spatial and temporal pattern of the year 2012 flood incidences; the area affected was estimated and the level of intensity was determined. This study has, therefore, provided a kind of baseline data for flood in the country, this can be built on and with time the trend can be analysed. Other effects are socioeconomic in nature, among which are inadequate food security both in the short and long term, death, sickness, destruction of houses, farmland, farm and animal produce as well as other critical infrastructure such as power lines, roads, bridges and water supply system. 
Without any doubt, the 2012 flood event in Nigeria has a lot of implications for the Nigerian environment and food security. Prominent among them are land degradation in the form of erosion, deforestation, distortion of surface morphology and pollution. As a result of the level of the effect of the flood, there is a need to be proactive in the management of flood events in the country in order to minimize their negative consequences (in particular inadequate food security) and enhance their benefits. Another step to be taken in the near future is the detailed examination of the socioeconomic implications of the flood on Nigeria and to suggest the way forward.

\section{Acknowledgements}

Thanks to the Nigerian Defence Academy that provided some financial support, F. Ajakaiye who prepared the figures and B. Helda who drew the maps.

\section{References}

Abel, N. O. J. (1993). What's in a Number? The Carrying Capacity Controversy of the Communal Rangeland of the Southern Africa. Norwich, School of Development Studies, Univ. of East Anglia. Monogr. 14.

Adewuyi, T. O. (2011). Land Degradation in the Peri-Urban Area: The case of Kaduna Metropolis, Nigeria (p. 158). Germany: Lambert Academy Publishing.

Adewuyi, T. O., \& Baduku, A. S. (2012). Recent consequences of land degradation on Farmland in the peri-Urban area of Kaduna Metropolis, Nigeria. Journal of Sustainable Development in Africa, 14(3), 179-193.

Ash, A. J., Stafford Smith, D. M., \& Abel, N. (2002). Land Degradation and Secondary Production in Semi-Arid and Arid Grazing Systems: What is the Evidence? In J. F. Reynolds \& D. M. Stafford Smith (Eds), Global Desertification: Do Humans Cause Deserts (pp. 111-134)? Workshop Report 88. Berlin: Dahlem University Press.

Dean, W. R. J., \& McDonald, J. A. W. (1994). Historical changes in stocking rates of domestic livestock as a measure of semi-arid and arid rangeland in the Cape Province, South Africa. J. Arid Env., 26, 281-298. http://dx.doi.org/10.1006/jare.1994.1030

Edosowman, N. L., \& Aigbe, G. (1998). Application of aerial photo-interpretation technique in mapping erosion risk area of Western Nigeria, Nigeria. JOSAMS, BUK., 5, 1-11.

Fagbami, A. A., \& Ogunkunle, A. O. (2000). Soil Survey, Land Evaluation and Agronomy: The Nigeria Case Study. In M. O. Akoroda (Ed.), Agronomy in Nigeria. Ibadan: Polygraphics Venture Limited.

Food and Agricultural Organisation. (1980). Land and Water Development. FAO, Rome.

Food and Agricultural Organisation. (1983). World Food Security: a Reappraisal of the Concepts and Approaches. Director General's Report, Rome

Food and Agricultural Organisation. (1993). FELSM: An International Framework for Evaluating Sustainable Land Management. World Soils Resources Reports, FAO No.73. Rome.

Food and Agricultural Organisation. (2002). The State of Food Insecurity in the World 2001. Rome.

Hiernaux, P., \& Turner, M. D. (2002). The Influence of Farmer and Pastoralist Management Practices on Desertification Processes in the Sahel. In J. F. Reynolds, \& D. M. Stafford Smith (Eds), Global Desertification: Do Humans Cause Deserts? Workshop Report 88 (pp. 135-148), Dahlem University Press, Berlin.

InterAcademy Council. (2004). Realizing the promise and potential of African Agriculture. Amsterdam.

Kapos, V. (2000). Original Forest Cover Map, Cambridge, UK: UNDP-WCMC.

Mallo, I. Y. Y. (2000). The Physical Environment as Bedrock for Better Quality of Life in Rural Nigeria. In S. A. Sati, \& A. A. Lipede (Eds), Transition and Development Process in Nigeria (pp. 198-227). Kaduna, Nigeria: Mahanaim Publication.

Maxwell, S. (1996). Food Security: a post-Modern Perspective. Food Policy, 21(2), 155-170. http://dx.doi.org/10.1016/0306-9192(95)00074-7

Maxwell, S., \& Smith, M. (1992). Household Food Security: a Conceptual Review. In S. Maxwell \& T. R. Frankenberger (Eds), Household Food Security: Concepts, Indicators, Measurements: A Technical Review. New York and Rome: UNICEF and IFAD.

Mortimore, M. (1989). Adapting to Drought: Farmers, Farming and Desertification in West Africa. Cambridge. 
Mwaniki, A. (n.d.). Achieving Food Security in Africa: Challenges and Issues. Cornell University, U.S., Plant, Soil and Nutrition laboratory. Retrieved November 09, 2013, from http://www.un.org/africa/osaa/reports/achieving....

Olofin, E. A. (1997). Consequences of Environmental Degradation on Man and Habitat. Workshop on Environmental Education, BUK, Nigeria.

Population Reference Bureau. (2012a). 2012 World Population Data Sheet. Washington, DC, USA.

Population Reference Bureau. (2012b). Population and Food Security: Africa's Challenge. Washington, DC, USA.

Pretty, J. N. (1994). Alternative Systems of Inquiry for a Sustainable Agriculture. IDS Bulletin 25, Institute of Development Studies, University of Sussex, Brighton. http://dx.doi.org/10.1111/j.1759-5436.1994.mp25002004.x

Redcliff, M. (1999). Sustainability: Life Chances and Livelihoods. Routledge, London.

Sneddon, C. S. (2002). Sustainability in ecological economics, ecology and livelihoods: a Review. Progress in Human Geography, 24(4), 521-549. http://dx.doi.org/10.1191/030913200100189076

United Nations Economic Commission for Africa. (2012). The Status of Food Security in Africa. Eighth session of the committee on food security and sustainable development and regional implementation meeting for the twentieth session of the commission on sustainable development, Addis Ababa, Ethiopia, 19-21 November, 2012. Retrieved November 09, 2013, from http://www.uneca.org/sites/default/file/page

United Nations Environmental Programme. (1985). Desertification Control in Africa. Desertification Control Programme Activity Centre. UNEP, Actions and Directory of Institutions, Nairobi. Vol 1, 126.

United Nations. (1975). Report of the World Food Conference, Rome, 5-16, November, 1974. New York.

World Resources Institute. (1997). The Last Frontier Forest: Ecosystems and Economics on the Edge. Washington, D.C. Retrieved June 28, 2013, from http://www.wri.org/wri/ffi/lff-eng

Xue, Y., \& Fennessy. (2002). Under What Conditions Does Land-Cover Change Impact Regional Climate? In J. F. Reynolds \& S. Stafford (Eds), Global Desertification: Do Humans Cause Deserts (pp. 59-74)? Workshop Report 88, Berlin: Dahlem University Press.

\section{Copyrights}

Copyright for this article is retained by the author(s), with first publication rights granted to the journal.

This is an open-access article distributed under the terms and conditions of the Creative Commons Attribution license (http://creativecommons.org/licenses/by/3.0/). 